Research Article

\title{
THE EFFECTS OF WELDING PRESSURE AND REINFORCEMENT RATIO ON WELDING STRENGTH IN DIFFUSION-BONDED AIMg3/SiCp COMPOSITES
}

\begin{abstract}
Nilhan ÜRKMEZ TAŞKIN ${ }^{1}$, Rifat YAKUT ${ }^{2 *}$, Engin ALP ${ }^{3}$
In this study, using the diffusion welding method, welded joints were created with AlMg3/SiCp composite materials, and the mechanical strengths of these joints were examined. The AlMg3/SiCp composite specimens were cut out of plates produced directly with the semi-solid stir-squeeze casting method and contained 10\% SiCp and 20\% SiCp reinforcement. To examine the effects of reinforcement ratios on joint strength, specimen couples with the same and different reinforcement ratios were created. To examine the effects of different welding pressures on joint strength, by keeping the welding temperature constant at $580^{\circ} \mathrm{C}$, welding was performed under 3 different pressures as $1.5 \mathrm{MPa}, 2.5 \mathrm{MPa}$ and $3.5 \mathrm{MPa}$. By determining the mechanical strengths of the welded joints that were formed by shear test, the effects of reinforcement ratios and welding pressures on joint strength were investigated. As a result of the shear tests applied on the welded specimens, in the specimens that were diffusion-welded, welding quality decreased based on increasing reinforcement ratios, but as the amount of pressure and application duration increased, joint strength increased. As the $\mathrm{SiC}$ ratio increased in the joint zones, diffusion became difficult, and weak joints were obtained. The microscopic structure of the joint zone was examined by using optical microscopy and scanning electron microscopy (SEM). It was seen that diffusion welding could be successfully performed in bonding SiCpreinforced aluminium composites if the suitable welding pressure and duration are selected.
\end{abstract}

Key words: Diffusion Welding, Aluminium, SiC, Metal Matrix Composites, Shear Test.

\section{Introduction}

Metal matrix composite (MMC) materials are advanced materials that have increasing usage rates in almost all industrial fields, especially defence, automotive and aviation [1-3]. A selected metal or metal alloy matrix material may not only be strengthened with reinforcements in micro/nano dimensions and different forms, but all thermal processes and cold forming methods that can be

\footnotetext{
1 Department of Mechanical Engineering, University of Trakya, Edirne, Turkey, (nilhanurkmez@gmail.com) iD https://orcid.org/0000-0003-2251-3889

2 Department of Energy Systems Engineering, University of Batman, Batman, Turkey, (rifat.yakut@batman.edu.tr) iD https://orcid.org/0000-0003-0059-3785

3 Department of Mechanical Engineering, University of Trakya, Edirne, Turkey, (enginalp@hotmail.com) iD https://orcid.org/0000-0002-1881-1675
} 
applied on the metal or metal alloy selected as the main matrix material may also be performed [4]. Although MMCs continue to be used and developed in almost every sector, it is one of the main problems that need to be overcome that, in bonding applications of these materials with different metals or themselves, the superior technical properties gained in production cannot be transferred to the joint zone [5-7]. Especially in bonding applications of particle-reinforced composite materials with fusion welding, different densities of the reinforcement material and the matrix material lead to separation of the matrix material that goes into a liquid form and the reinforcement materials in various forms, failure of achieving the reinforcement distribution before the welding process and formation of segregation zones $[8,9]$. Besides this, problems such as formation of unwanted reaction products due to processing temperatures higher than the melting temperature, uncontrolled solidifications that form during cooling or cracking of welding zones by excessive reduction of the ductility of the material are also frequently encountered [10-14]. In solid-state welding methods where melting does not take place, it is aimed for the materials to be bonded to preserve their structures and properties before the welding process, while the welding parameters in the diffusion bonding/welding method are temperature, pressure, duration of pressure application and atmosphere, welding zones with adequate mechanical properties may be obtained by providing the optimum values, and this method may also be used to bond MMCs according to the reports in the literature [15-23]. However, welding particle-reinforced aluminium composites is difficult and requires taking special precautions. Systematic work on this issue has been encountered in very few studies, and in this study, the weldability of MMC materials containing different reinforcement ratios was examined. Composite specimen couples with the same and different reinforcement ratios were prepared from $\mathrm{AlMg} 3 / \mathrm{SiCp}$ composite blocks, and the prepared specimens were subjected to diffusion welding at the temperature of $580^{\circ} \mathrm{C}$ and under pressures of $1.5 \mathrm{MPa}, 2.5 \mathrm{MPa}$ and $3.5 \mathrm{MPa}$. To determine the effects of reinforcement ratios on joint strength, shear and microhardness tests were applied, and the microstructures of the bonded-welded joints were examined by optical microscopy and SEM.

\section{Experiments}

\subsection{Materials}

The specimen material consisted of AlMg3/SiCp composite material obtained by the semi-solid stir and squeeze casting method. This method is described in a patent held by Urkmez Taskin and Taskin $[23,24]$. As the matrix material in the composite materials to be subjected to diffusion welding, the AlMg3 (EN AW 5754) aluminium alloy, which has good weldability, ductility and toughness properties and excellent corrosion resistance especially against seawater, was used. The chemical, mechanical and physical properties of AlMg3 are shown in Tables 1 and 2. As the reinforcement material, SiCp particles with grain sizes of 500 Mesh $(\sim 12 \mu \mathrm{m})$ were utilized. With semi-solid stirring, the reinforcement material can be homogenously stirred into the matrix alloy in the desired ratio, and during stirring, problems such as flocculation of the reinforcement, separation from the mixture or precipitation are not encountered. Additionally, as reinforcement addition takes place at a relatively lower temperature than liquid stirring methods, formation of unwanted reaction products is minimized $[20,23,25]$. 
Table 1. Chemical composition of the AlMg3 alloy [23]

\begin{tabular}{|c|c|c|c|c|c|c|c|c|c|}
\hline $\mathbf{F e}$ & $\mathbf{S i}$ & $\mathbf{M n}$ & $\mathbf{C r}$ & $\mathbf{T i}$ & $\mathbf{C u}$ & $\mathbf{B e}$ & $\mathbf{M g}$ & $\mathbf{Z n}$ & - \\
\hline $\max$ & $\max$ & $\max$ & $\max$ & $\max$ & $\max 0.1$ & $\max$ & $2.6-3.6$ & $\max 0.2$ & $\begin{array}{c}0.1<\mathrm{Mn}+\mathrm{Cr}<0.6 \\
\text { Al-remainder }\end{array}$ \\
\hline
\end{tabular}

Table 2. Mechanical and physical properties of the AIMg3 alloy and composite specimens [23]

\begin{tabular}{|l|c|c|c|}
\hline & AlMg3 & AlMg3/SiCp (vol 10\%) & AlMg3/SiCp (vol 20\%) \\
\hline Brinell hardness (HBW): (O) (H111) & 45 & 100 & 148 \\
\hline Tensile strength (MPa) (F) (H112) & 180 & 210 & 245 \\
\hline Proof strength (MPa) (F) (H112) & $70-80$ & 190 & 210 \\
\hline Density, g/cm ${ }^{3}$ & 2.66 & 2.91 & 76 \\
\hline Young Modulus, GPa & $68-72$ & 70 & - \\
\hline Shear Modulus, GPa & 27 & - & - \\
\hline Melting Temperature, ${ }^{\circ} \mathrm{C}$ & $600-640$ & - & 10 \\
\hline A-Min. elongation at fracture (\%) (F) (H112) & $13-14$ & 12 & \\
\hline
\end{tabular}

\subsection{Diffusion welding furnace and shear test apparatuses}

For the diffusion welding process, the diffusion welding furnace whose picture is seen in Figure 1 was designed and produced. The picture of the apparatus that was designed for placing the specimens into the diffusion welding furnace and forming welded joints is shown in Figure 2, while the specimen dimensions are shown in Figure 3.

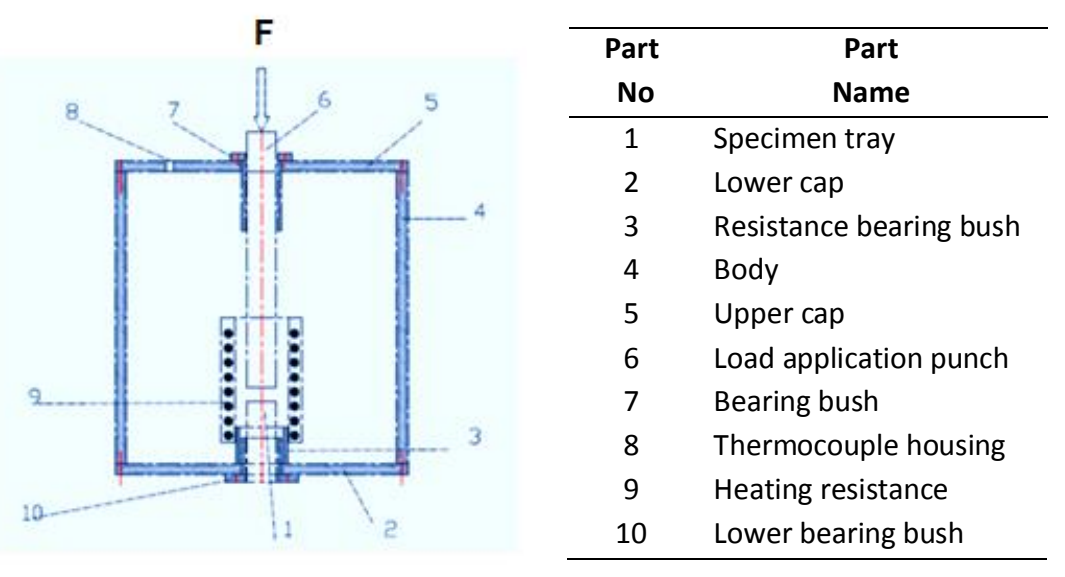

Figure 1. Schematic drawing of Diffusion bonding apparatus [25]

Diffusion welding apparatuses were designed and produced out of steel material with the machining method. The welded specimens [28] had dimensions of $25 \mathrm{~mm} \times 12 \mathrm{~mm} \times 3 \mathrm{~mm}$, while the shear specimens were obtained by cutting these specimens into 3 parts with dimensions of $8 \mathrm{~mm} \times 12 \mathrm{~mm} \times$ $3 \mathrm{~mm}$ (Figure 3). For applying the shear test, a shear apparatus was designed in compliance with the jaws of the INSTRON 1501 universal device and produced (Figure 4).

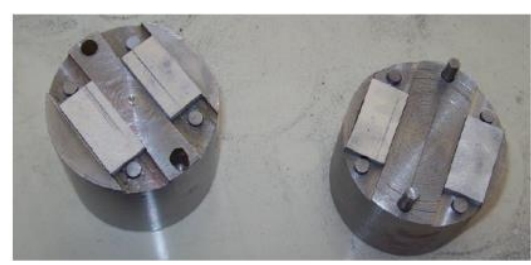

Figure 2. Diffusion bonding fixture [25]
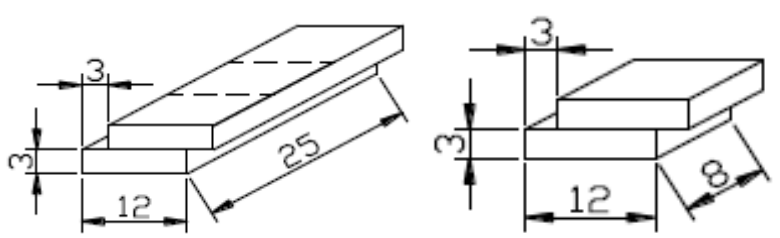

Figure 3. Dimensions of diffusion and shear test specimens [25] 


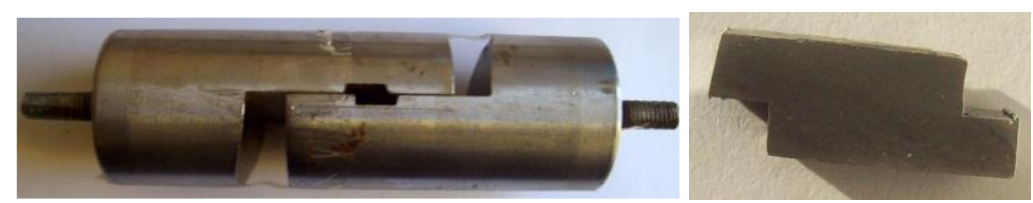

Figure 4. Apparatus for the shear test and the diffusion bonded shear test specimen photo [25]

\subsection{Diffusion Welding}

The diffusion welding specimens were cut out of AlMg3 composite blocks with dimensions of $25 \mathrm{~mm} \times 12 \mathrm{~mm}$ x $3 \mathrm{~mm}$ using the wire erosion method. The cut specimens were placed onto each other in the welding apparatus shown in Figure 2 and joined. In the diffusion welding process, welding temperature, duration and pressure values were selected by considering studies in the literature. In the trial welding processes, welding was performed when the welding temperature was in the range of 560 - $590^{\circ} \mathrm{C}$, and thus, the welding temperature was selected as $580^{\circ} \mathrm{C}$. The diffusion welding process was performed under normal atmosphere and without using an intermediate layer. Two different times as $120 \mathrm{~min}$ and $180 \mathrm{~min}$ were selected as the welding durations. The welding duration started as soon as the temperature of the specimens reached $580^{\circ} \mathrm{C}$. During the process, the temperature was constantly controlled. The specimens were cooled by themselves inside the furnace and under a fixed load.

The literature was taken as a basis for the pressure values to be applied in the diffusion welding process. For the diffusion welding of Al-based $\mathrm{SiC}$ particle-reinforcement composite materials, by conducting trials in the interval of 1-5 MPa, the lower pressure value for bonding to start was determined as $1.5 \mathrm{MPa}$, while the upper pressure value where plastic deformation started was determined as 3.5 MPa. In the same conditions, by performing welding procedures with the specified parametric values on the unreinforced matrix alloy, the reference specimens were prepared. Using three different pressure values and two different durations, 2 specimens for each case were joined by diffusion welding. The welding pressures and times used in this study are shown in Table $3[23,26]$.

Table 3. Diffusion bonding parameters used in this study

\begin{tabular}{|l|c|c|c|}
\hline Material Combination & $\begin{array}{c}\text { Temperatu } \\
\text { re }\left({ }^{\circ} \mathbf{C}\right)\end{array}$ & $\begin{array}{c}\text { Welding } \\
\text { Pressure (MPa) }\end{array}$ & $\begin{array}{c}\text { Welding Time } \\
\text { (min) }\end{array}$ \\
\cline { 1 - 2 } AlMg3- AlMg3 & & & \\
\cline { 1 - 2 } AlMg3-AlMg3/SiCp, (vol 10\%) & \multirow{2}{*}{580} & 2.5 & 120 \\
\cline { 1 - 2 } AlMg3-AlMg3/SiCp, (vol 20\%) & & 3.5 & 180 \\
\cline { 1 - 2 } AlMg3/SiCp, (vol 10\%)-AlMg3/SiCp, (vol 10\%) & & \\
\cline { 1 - 2 } AlMg3/SiCp, (vol 20\%)-AlMg3/SiCp, (vol 20\%) & & \\
\hline
\end{tabular}

\subsection{Characterisation}

Each of the welded specimens was divided into three equal parts, and a total of 6 shear test specimens with the same conditions were prepared. The surfaces of the specimens to be welded were prepared with 100, 200 and 400 mesh sandpapers, and they were left in pure alcohol before the procedure. To determine the bond strength of the diffusion welded specimens, shear and hardness tests were applied. The shear tests were performed at a progression rate of $0.5 \mathrm{~mm} / \mathrm{min}$ with an INSTRON 8501 Universal test device by applying force in the compression direction. The microhardness tests were performed on the basis of the DIN EN ISO 6507-1 standard.

The welded specimens were firstly divided lengthwise into two and embedded in Bakelite. The specimens that were subjected to standard sanding and polishing procedures were finally subjected to 
etching. The metallographic examinations of the welded specimens were carried out by an optical microscope and by SEM.

\section{Results and Discussion}

The specimens that were bonded by diffusion welding were firstly macroscopically examined, and whether or not the welding pressure caused a deformation was determined. As seen in Table 4, a preliminary study was carried out under $1.5 \mathrm{MPa}, 2.5 \mathrm{MPa}$ and $3.5 \mathrm{MPa}$ of pressure and $120 \mathrm{~min}$ and $180 \mathrm{~min}$ of welding duration to determine the suitable pressure and duration. As the results obtained at the welding durations of $120 \mathrm{~min}$ and $180 \mathrm{~min}$ in the preliminary study were in parallel to each other, it was found appropriate in this study to use the welding duration of $180 \mathrm{~min}$. Whether or not joint formation took place and whether or not deformation was observed are shown in Table 4 regarding the material couples' welding procedure in the preliminary study. No deformation was observed in any of the specimen couples that were welded under the pressures of $1.5 \mathrm{MPa}$ and $2.5 \mathrm{MPa}$.

Table 4. Diffusion bond and deformation formation according to the applied pressure and time

\begin{tabular}{|c|c|c|c|c|c|}
\hline Material couple & $\begin{array}{c}\text { Temperature } \\
\left({ }^{\circ} \mathrm{C}\right)\end{array}$ & $\begin{array}{c}\text { Pressure } \\
\text { (MPa) }\end{array}$ & $\begin{array}{l}\text { Time } \\
\text { (dk) }\end{array}$ & Deformation & Bonding \\
\hline \multirow{6}{*}{ AlMg3 - Al Mg3 } & \multirow{6}{*}{580} & \multirow[t]{2}{*}{1.5} & 120 & - & - \\
\hline & & & 180 & No & + \\
\hline & & \multirow[t]{2}{*}{2.5} & 120 & No & - \\
\hline & & & 180 & No & + \\
\hline & & \multirow[t]{2}{*}{3.5} & 120 & Yes & + \\
\hline & & & 180 & Yes & + \\
\hline \multirow{6}{*}{ Al Mg3 - AlMg3/SiCp (10\%) } & \multirow{6}{*}{580} & \multirow[t]{2}{*}{1.5} & 120 & No & - \\
\hline & & & 180 & No & - \\
\hline & & \multirow[t]{2}{*}{2.5} & 120 & No & - \\
\hline & & & 180 & No & + \\
\hline & & \multirow[t]{2}{*}{3.5} & 120 & Partially & + \\
\hline & & & 180 & Partially & + \\
\hline \multirow{6}{*}{ AlMg3 - AlMg3/SiCp (20\%) } & \multirow{6}{*}{580} & \multirow[t]{2}{*}{1.5} & 120 & No & - \\
\hline & & & 180 & No & - \\
\hline & & \multirow[t]{2}{*}{2.5} & 120 & No & - \\
\hline & & & 180 & No & + \\
\hline & & \multirow[t]{2}{*}{3.5} & 120 & Partially & + \\
\hline & & & 180 & Partially & + \\
\hline \multirow{6}{*}{ AlMg3/SiCp (10\%) - AlMg3/SiCp (10\%) } & \multirow{6}{*}{580} & \multirow[t]{2}{*}{1.5} & 120 & No & - \\
\hline & & & 180 & No & - \\
\hline & & \multirow[t]{2}{*}{2.5} & 120 & No & - \\
\hline & & & 180 & No & + \\
\hline & & \multirow[t]{2}{*}{3.5} & 120 & No & + \\
\hline & & & 180 & Yes & + \\
\hline \multirow{6}{*}{ AlMg3/SiCp (20\%) - AlMg3/SiCp (20\%) } & \multirow{6}{*}{580} & \multirow[t]{2}{*}{1.5} & 120 & No & - \\
\hline & & & 180 & No & - \\
\hline & & \multirow[t]{2}{*}{2.5} & 120 & No & - \\
\hline & & & 180 & No & + \\
\hline & & \multirow[t]{2}{*}{3.5} & 120 & No & + \\
\hline & & & 180 & No & + \\
\hline
\end{tabular}

Deformation took place in the non-reinforced specimen couples and on the non-reinforced side in cases of welding with $10 \%$ and $20 \% \mathrm{SiCp}$-reinforced composites under the pressure of 3.5 $\mathrm{MPa}$. No 
deformation was observed on the reinforced sides. Under the same pressure, deformation did not occur after the welding process of $20 \% \mathrm{SiCp}$ and $10 \% \mathrm{SiCp}$-reinforced composites. No deformation was observed in the 20-20\% $\mathrm{AlMg} 3 / \mathrm{SiCp}$ specimen couple under 2.5 $\mathrm{MPa}$. There was negligible deformation in the $10-10 \% \mathrm{AlMg} 3 / \mathrm{SiCp}$ specimen couple under $3.5 \mathrm{MPa}$. The pressure value of 3.5 $\mathrm{MPa}$ was determined as the upper boundary of pressure in the diffusion welding process of $10 \% \mathrm{SiCp}-$ reinforced specimens. There was no deformation in the $20-20 \% \mathrm{AlMg} 3 / \mathrm{SiCp}$ specimens under 3.5 MPa.

The welded joints were examined under an optical microscope and by SEM. Figure 5 shows that, in the optical microscopic examinations of the specimens processed under a pressure of $1.5 \mathrm{MPa}$ for $120 \mathrm{~min}$, the welding zone lines were noticeable, and gaps and welding lines could not be eliminated in this zone.

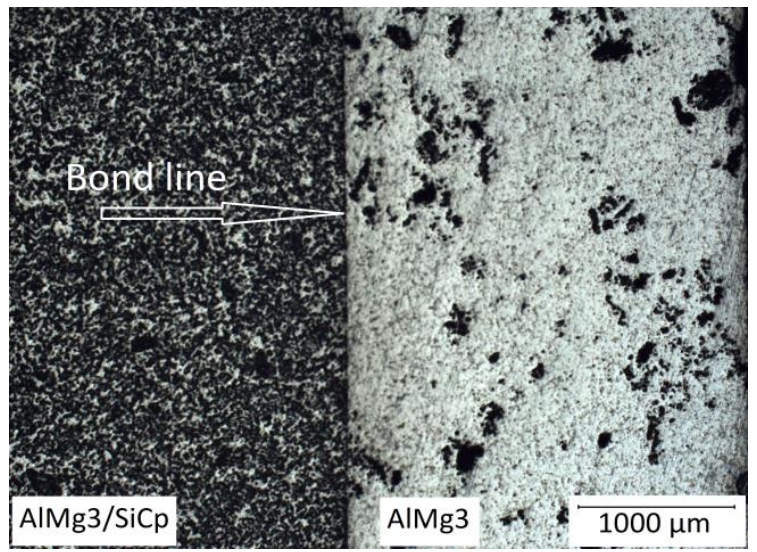

a)

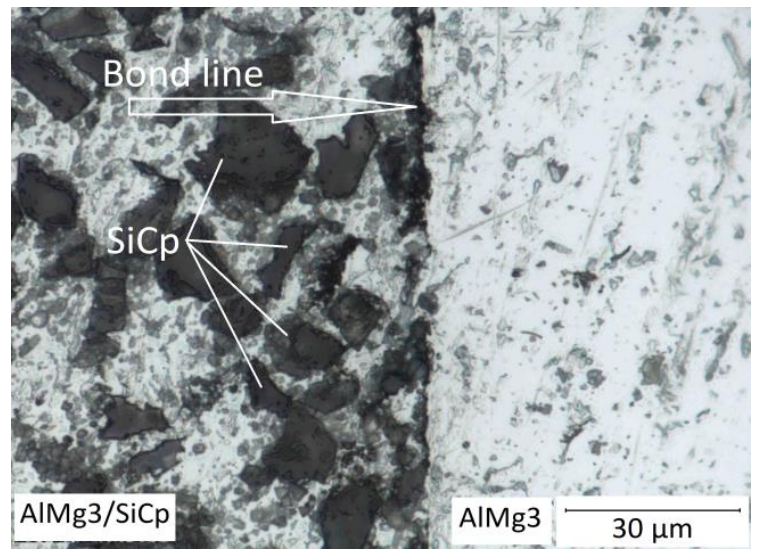

b)

Figure 5. Optical microscope images of the $\mathrm{AlMg} 3 / \mathrm{SiCp}(20 \%)$ - AlMg3 couple diffusion welded for 180 min under

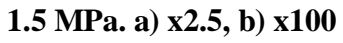

Figure 6a shows that there were gaps and pores of $\sim 1-5 \mu \mathrm{m}$ dimensions on the joint line in the bonding zones of the $\mathrm{AlMg} 3 / \mathrm{SiCp}$ (vol.20\%) - AlMg3specimens that were bonded under a pressure of $2.5 \mathrm{MPa}$ for $120 \mathrm{~min}$, whereas Figure $6 \mathrm{~b}$ shows that gaps and pores decreased on the joint line in the bonding zones of the $\mathrm{AlMg} 3 / \mathrm{SiCp}(\mathrm{vol} .20 \%)$ - AlMg3specimens that were bonded under a pressure of $2.5 \mathrm{MPa}$ for $180 \mathrm{~min}$.

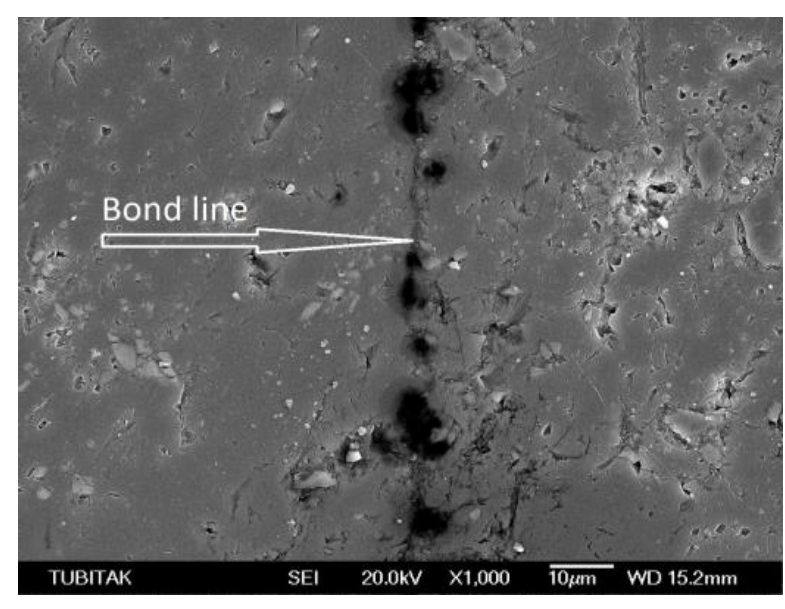

a)

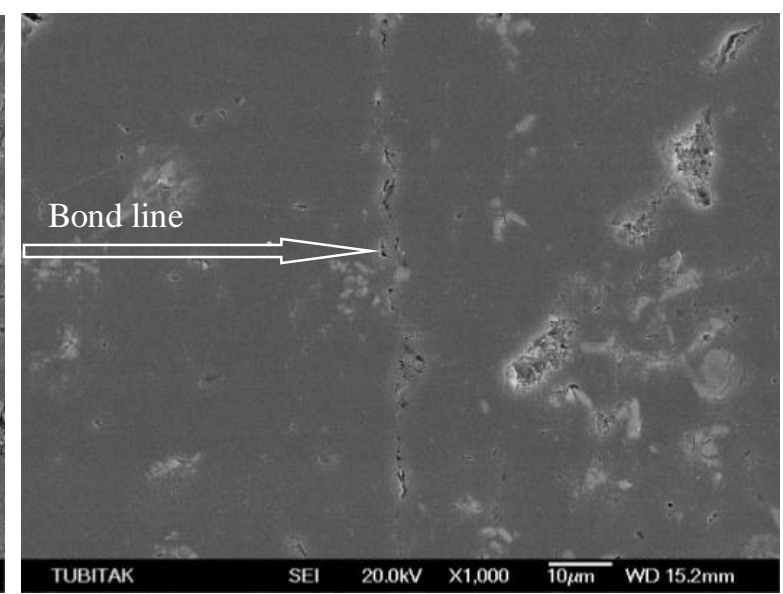

b)

Figure 6. SEM images of the bonded joints of AlMg3/SiCp (20\%) - AlMg3 samples under a) $2.5 \mathrm{MPa}$ pressure and $120 \mathrm{~min}$. b) $2.5 \mathrm{MPa}$ pressure and $180 \mathrm{~min}$. 
Figures $7 \mathrm{a}$ and $7 \mathrm{~b}$ show the bonding zones of the AlMg3 / SiCp (vol.20\%)-AlMg3 couple that were bonded for $180 \mathrm{~min}$ under a pressure of 3.5 MPa. Bonding occurred in the welding zone, and the line in the interface mostly became unnoticeable.
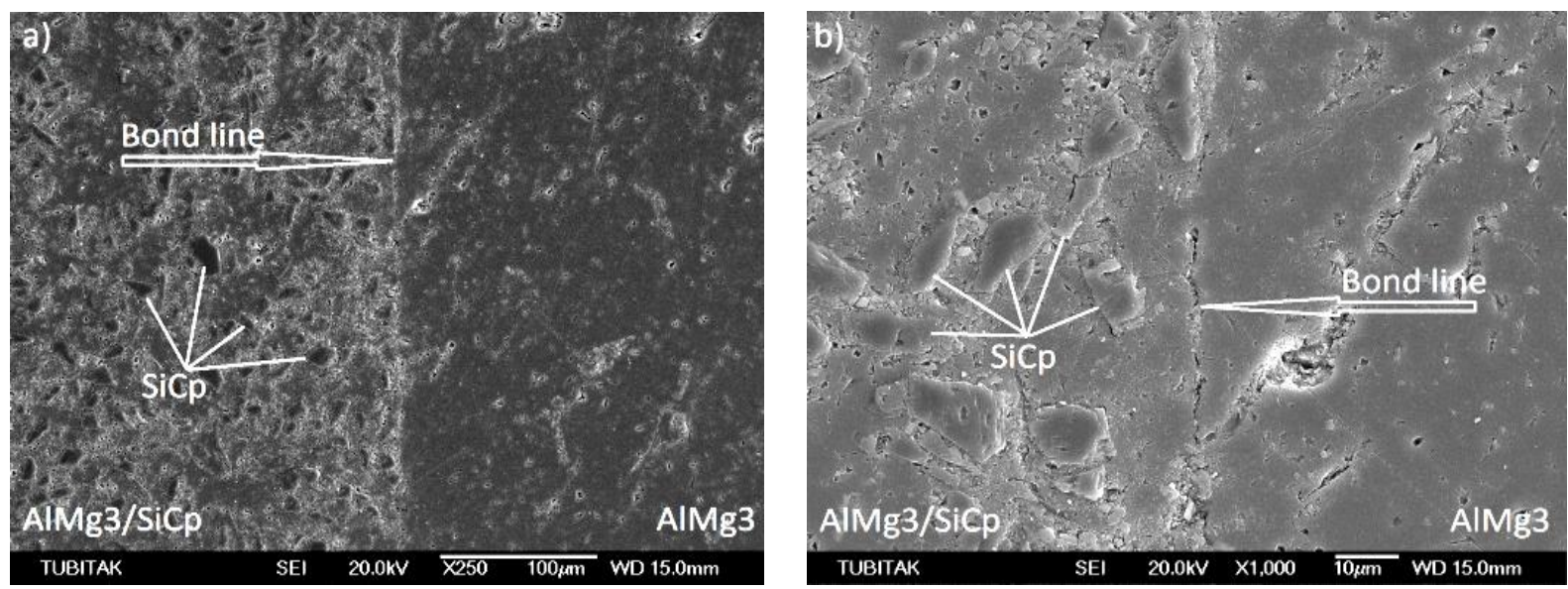

Figure 7. Optical microscope and SEM images of the AIMg3/SiCp (20\%) - AIMg3 couple diffusion-welded for $180 \mathrm{~min}$ under a pressure of 3.5 MPa. a) X250, b) X1000

As the diffusion welding pressure increased, there were increases in the shear strength of all specimens where bonding occurred. Moreover, in the welding process of the composites with a high reinforcement ratio, the reinforcement particles probably posed an obstacle to diffusion, and lower results were obtained in comparison to the shear strength of the non-reinforced material. When the joined specimens included a high ratio of reinforcement, for example, in the case that both parts included $20 \%$ of reinforcement, and $1.5 \mathrm{MPa}$ of pressure and $120 \mathrm{~min}$ of time were applied, bonding did not occur completely, and very low shear strength values were obtained. With the increase in the welding time and pressure, bonding occurred in the composite materials with high reinforcement ratios, and the shear strength values increased. The highest shear strength values were obtained in the diffusion welding process of the non-reinforced specimens, while as the welding pressure that was applied increased, the shear strength values showed an increase. These results were in good agreement with the studies by Cooke et al. (2012) and Zhang et al. (1999). In both these studies, it was stated that the strength of diffusion bonded joints decreases with increasing $\mathrm{SiCp}$ volume percentage. In the welding of the composite materials with the welding parameters in this study, the highest shear strength was obtained in the specimen couple where $\mathrm{AlMg} 3$ / $\mathrm{SiCp}($ vol.10\%)-AlMg3 were bonded for $180 \mathrm{~min}$ under a pressure of 3.5 MPa. If the shear test results are interpreted, it is seen that the reinforcement rate affected the quality of welding in the diffusion welding process of the particlereinforced composite materials. In this study that was in parallel with similar studies in the literature, the SiCp particles in the bonding zone affected the success of diffusion welding negatively, and joints with low strengths were obtained. Increased welding pressure and time led to an increase in joint strength [26, 27]. The lowest shear strength was obtained at a $1.5 \mathrm{MPa}$ bonding pressure in the AlMg3 / $\mathrm{SiCp}$ (volume 20\%) composite couples, and the highest shear strength was obtained at a $3.5 \mathrm{MPa}$ bonding pressure in the $\mathrm{AlMg} 3 / \mathrm{SiCp}($ vol.10\%)- $\mathrm{AlMg} 3$ couples. For the bonded joints produced at the bonding time of 120 minutes, not enough diffusion bond was provided for all samples. Figure 8 shows the plot of the change in the shear strength of the samples with the diffusion bonding pressures in 180 minutes of bonding time. 


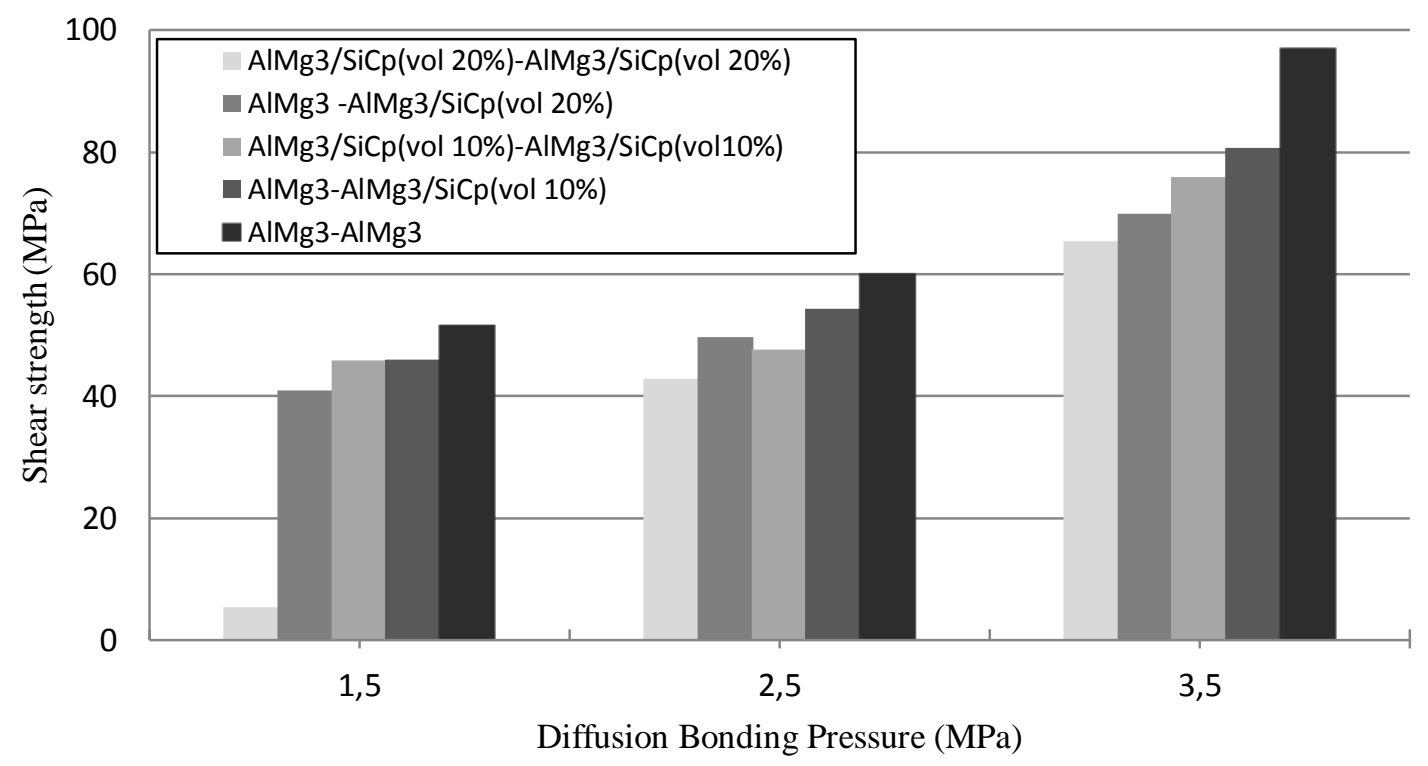

Figure 8. Shear test results at different bonding pressures and the welding duration of 180 min

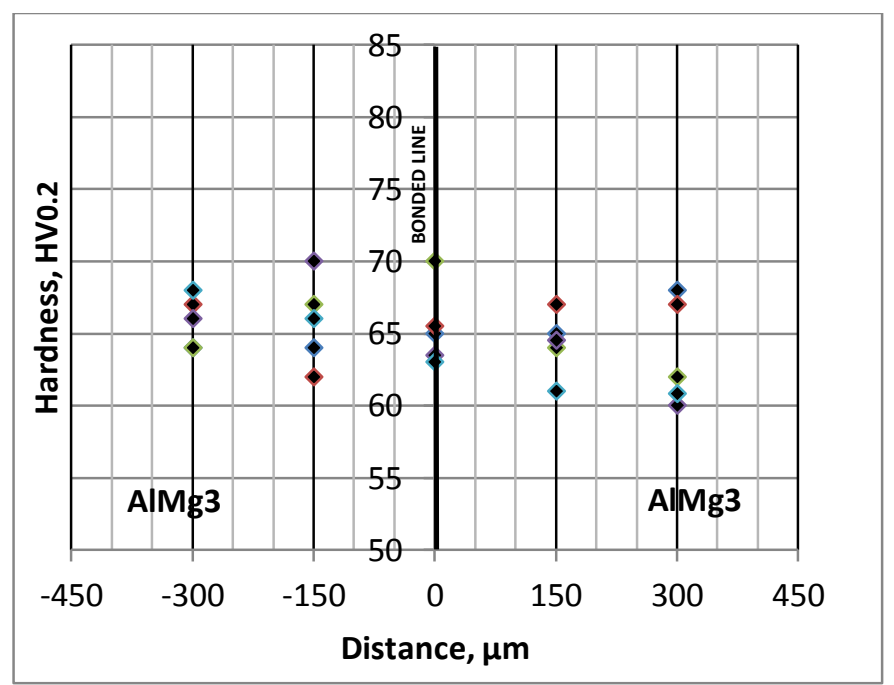

(a)

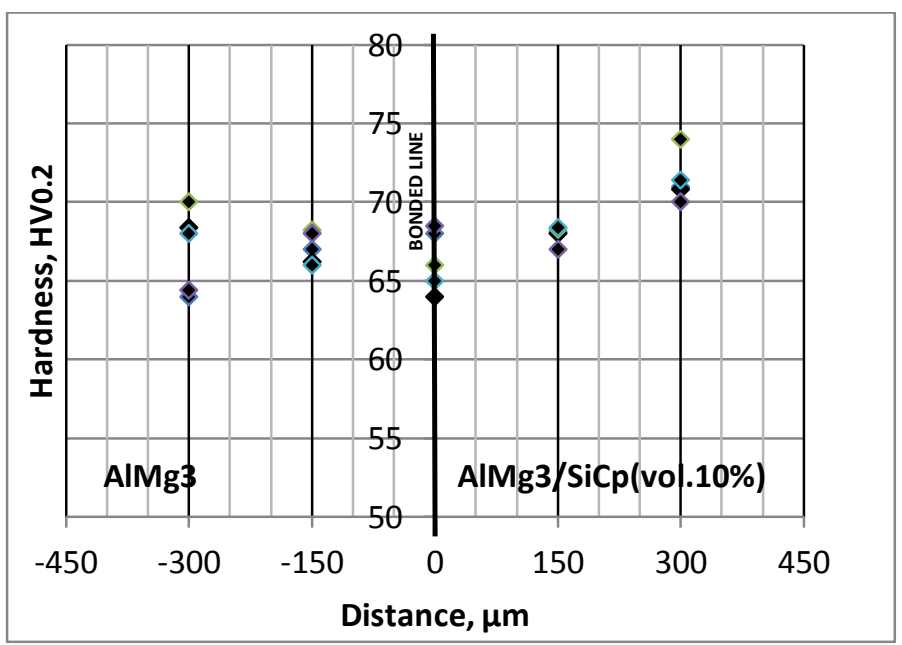

(b) 


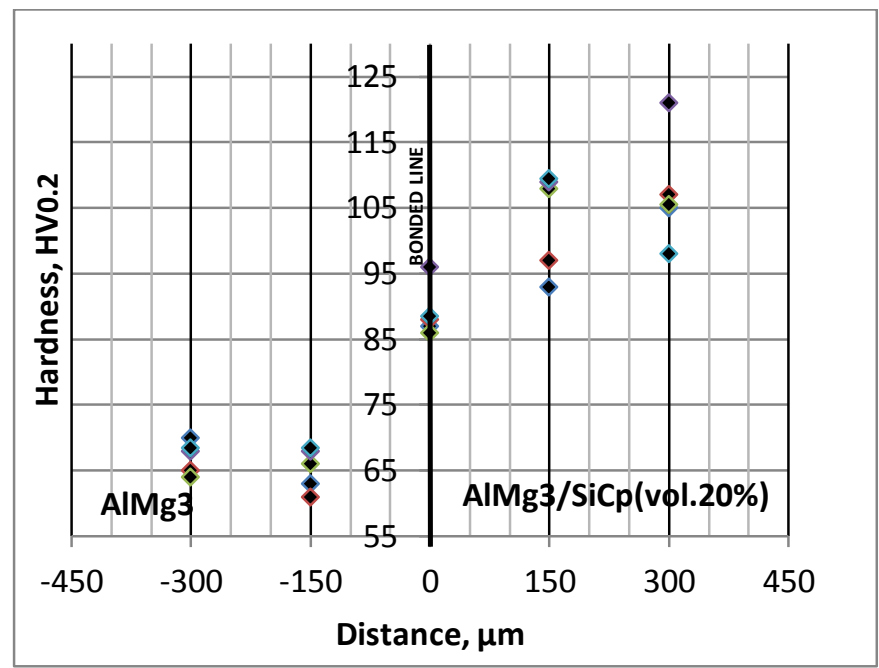

(c)

Fig.9. Hardness profiles across the bonded line, (a) AlMg3-AlMg3 (b) AlMg3-AlMg3/SiCp (vol.10\%) (c) AlMg3$\operatorname{AlMg} 3 / \mathrm{SiCp}($ vol.20\%)

The microhardness profiles for across the bond line for the AlMg3/AlMg3 and AlMg3/SiCpAlMg3 couples (3.5 MPa/180min) are shown in Fig. 9. In all conditions, the hardness values in all regions were higher than the hardness values of the base (AlMg3) materials. Fig. 9a shows the crosssection of the bond line of the AlMg3-AlMg3 couple. The hardness profile shows the almost homogeneous distribution in the bond regions of these samples. The highest hardness value as 70 HV0.2 was measured in this sample. In welded joints formed used the AlMg3/SiCp composites and the $\mathrm{AlMg} 3$ matrix alloys, the hardness values in the bond region were measured as higher than the matrix material's hardness values. The highest hardness value on the side of the AlMg3/SiCp (vol.10\%) composite was found as $74 \mathrm{HV0.2}$, and the hardness value on bonded line was 68 HV0.2 (Fig. 9b). Fig. 9c shows the cross-section of the bond line of the AlMg3-AlMg3/SiCp (vol\%20) couple. In this sample, a hardness peak was observed close to the interface on the composite side. When the holding time was increased from $120 \mathrm{~min}$ to $180 \mathrm{~min}$, hardness was also increased. Likewise, by increasing the welding pressure from 2.5 MPa to 3.5 MPa, hardness was also increased. It was found that the side of the $\mathrm{AlMg} 3 / \mathrm{SiCp}$ (vol.20\%) composite at a $3.5 \mathrm{MPa}$ pressure had the maximum hardness value as 124 HV0.2. Moreover, the hardness value on the AlMg3 matrix alloy was $68.5 \mathrm{HV} 0.2$, and the hardness value on the bonded zone was nearly the same values. These results were in good agreement with the studies by Muratoglu et al. (2006) and Mollaoglu et al. (2006). In both these studies, it was stated that the hardness values of diffusion bonded joints increase by increasing SiCp volume percentage, and when the bonding time increases, the bonding strength increases, too. Bonding time has a significant effect on the diffusion bonding process.

\section{Conclusions}

The following conclusions may be drawn from this study:

a) $\mathrm{The} \mathrm{AlMg} 3$ / $\mathrm{SiCp}$ - $\mathrm{AlMg} 3$ couples were successfully diffusion-bonded for all welding pressures at a $580^{\circ} \mathrm{C}$ bonding temperature for 180 min holding times. The AlMg3couples 
were bonded with diffusion at lower pressures in comparison to the composite samples. It was observed that their shear strength was higher than the composite couples.

b) The shear strength of the AlMg3 / SiCp (vol.20\%) composite couples was lower than the $\mathrm{AlMg} 3$ / SiCp (vol.10\%) and $\mathrm{AlMg} 3$ couples at all pressures. As the reinforcement rate was increased in the composite samples, deformation decreased at all bonding pressures.

c) As the diffusion pressure and bonding time increased, the shear strength increased in all samples.

d) The strength of the diffusion-bonded joints decreased with increasing $\mathrm{SiCp}$ volume percentage. The hardness values of the diffusion bonded joints increased with increasing the SiCp volume percentage. Moreover, bonding time had a significant effect on the diffusion bonding process.

\section{References}

[1] Zhang X.P., Ye 1., Mai W.Y., et.al., Investigation on Diffusion Bonding Characteristics of SiC Particle Reinforced Aluminum Metal Matrix Composites (Al/SiCp MMC) Composites. Part A: Appl. Sci.Manuf. 30, 12, 1415 1421, 1999.

[2] Garg, P., Jamwal, A., Kumar, D., Sadasivuni, K. K., Hussain, C. M., Gupta, P. (2019). Advance research progresses in aluminium matrixcomposites: Manufacturing \& applications, Journal of Materials Research and Technology, 8 (5), 4924-4939.

[3] Rosso, M. (2006). Ceramic and metal matrix composites: Routes and properties, Journal of Materials Processing Technology, 175 (1-3), 364-375.

[4] Kaczmar, J. W., Pietrzak, K., Wlosinski, W. (2000). The production and application of metal matrix composite materials, Journal of Materials Processing Technology, 106 (2000), 58-67.

[5] Ellis, M. B. D. (2007). Joining of Al-based metal matrix composites - A review, Materials and Manufacturing Processes 11 (1), 45-66.

[6] Arık, H., Aydın, M., Kurt, A., Türker M. (2005). Weldability of $\mathrm{Al}_{4} \mathrm{C}_{3}-\mathrm{Al}$ composites via diffusion welding tecnique, Materials and Design, 26 (6), 555-560.

[7] Uluköy, A., Onar V., Kaplan, Y. (2015). The microstructure and hardness properties analysis of welded aluminum matrix material reinforced with sic using different currents and forms of welding" Pamukkale University Journal of Engineering Sciences, 21 (8), 365-370.

[8] Karakoç, H., Çıtak, R., (2017). Study on weldability of $b_{4} c$ reinforced aluminium composite materials with TIG welding, El-Cezerî Journal of Science and Engineering, 4 (3), 584-592.

[9] Storjohann, D., Barabash, O.M., Babu, S.S., David, S.A., Sklad, P.S., Bloom, E.E., (2005). Fusion and friction stir welding of aluminum-metal-matrix composites, Metallurgical and Materials Transactions A-Physical Metallurgy and Materials Science, 36 (11), 3237-3247.

[10] Lean, P. P., Gil, L., Urena, A., (2003). Dissimilar welds between unreinforced AA6082 and AA6092/SiC/25p composite by pulsed-MIG arc welding using unreinforced filler alloys (Al-5Mg and Al-5Si), Journal of Materials Processing Technology 143-144 (2003), 846-850.

[11] Mollaoğlu, H., Diffusion bonding of SiC partilucate reinforced Al metal matrix composites, Yildiz Technical University, Institute of Science and Technology, Master of Science Thesis, İstanbul, 2004.

[12] Buytoz, S., The investigation of weldability of al matrix - $\mathrm{Al}_{2} \mathrm{O}_{3}$ reinforced composite materials with solid state bonding methods, Frrat University, Institute of Science and Technology, Master of Science Thesis, Elazı̆̆ 1999. 
[13] Çalıülü, U., The investigation of joinability of with hot pressing manufactured AlSiMg-SiCp reinforced composites, Firat University, Institute of Science and Technology, Master of Science Thesis, Elazı $\breve{g}$, (2005).

[14] Çelik, S., An investigation of diffusion welding parameters for pure aluminum and copper in inert gas, Balıkesir University, Institute of Science and Technology, Ph.D. Thesis, Balıkesir, 1996.

[15] Kaya, M., Kılıç, M., Kırık, I., Karakurt, E. M., Gülenç, B., (2017). Diffusion bonding between Ti6Al-4V alloy and interstitial free steel, Mat.-wiss. u. Werkstofftech., 48, 1-5.

[16] Dikbaş, H., The investigation of bondability of Ni-Ti alloys by powder metallurgy method with the diffusion bonding, Firat University, Institute of Science and Technology, Master of Science Thesis, Elazı̆̆, (2005).

[17] Erden, İ. O., Investigation of weldability of $\mathrm{Al}-\mathrm{Si}_{3} \mathrm{~N}_{4}$ composite materials by diffusion welding, Gazi University, Institute of Science and Technology, Master of Science Thesis, Ankara, 2005.

[18] Mollaoğlu, H., Diffusion bonding of SiC partilucate reinforced Al metal matrix composites, Yildiz Technical University, Institute of Science and Technology, Master of Science Thesis, İstanbul, 2004.

[19] Çelik, Y. H., Kılıçkap, E., Yenigün, B. (2018). The effect of contact pressure and $\mathrm{B}_{4} \mathrm{C}$ ratio on hardness and wear behaviours in Al-matrix composites produced by PM method, Science and Eng. J of Firat Univ., 30 (1), 33-40.

[20] Yakut R., Ürkmez Taşkın, N. (2019). Production of AA7075/B $\mathrm{B}_{4} \mathrm{C}$ composite materials by the semi-solid stirring method, European Journal of Technique (EJT), 9 (2), 230-240.

[21] Adin, H., Seven, B., Çakar, F., Yıldırım, H., Ataş, İ. (2017 ). Experimental determination of the mechanical properties of composite materials produced with particle reinforced adhesives, European Journal of Technique (EJT), 7 (2), 158-164.

[22] Yakut R., Ürkmez Taşkın, N. (2018). Production of AA7075 / B4C / SiC hybrid composite materials by semi-solid stirring method, 1st Internatıonal Engıneering And Technology Symposium (1st Iets) 03-05 May, Batman / Turkey

[23] Ürkmez, N., Production of $\mathrm{AlMg} 3 / \mathrm{SiCp}$ composites and investigations of variations in mechanical properties, Yildiz Technical University, Institute of Science And Technology, Ph.D. Thesis, İstanbul, 2004.

[24] Ürkmez Taşkın, N., Taşkın, V. (2015). Continuous Composite Metal Foam production and method and device for stirring particle reinforced composite metal, European Patent Office, Espacenet Patent Publication Number: WO2015094139A2

[25] Alp, E., Investigation of weldability of AlMg3/SiCp composites, Trakya University, Institute of Science and Technology, Master of Science Thesis, Edirne, 2008.

[26] Muratoğlu, M., Yilmaz, O., Aksoy, M. (2006). Investigation on diffusion bonding characteristics of aluminum metal matrix composites $(\mathrm{Al} / \mathrm{SiCp})$ with pure aluminum for different heat treatments, Journal of Materials Processing Technology,178, 211-217.

[27] Özdemir, U., Microstructural and mechanical characterization of diffusion bonded TiAl and Ti6A14V alloys, Mustafa Kemal University, Institute of Science and Technology, Master of Science Thesis, Hatay, 2003.

[28] Cooke, Kavian \& Khan, Tahir \& Oliver, Gossett. (2012). Transient liquid phase diffusion bonding Al-6061 using nano-dispersed Ni coatings. Materials \& Design. 33. 469-475. 10.1016/j.matdes.2011.04.051. 